\title{
PENGARUH KOMITMEN, PERILAKU PEGAWAI, KEMAMPUAN KERJA DAN PENGAWASAN TERHADAP KINERJA PEGAWAI PADA KANTOR WILAYAH DJP SUMATERA UTARA I
}

\author{
Dindin Syahrudin \\ Universitas Islam Sumatera Utara \\ dindin.syahrudin@gmail.com
}

\begin{abstract}
The formulation of the problem in this study are: How does the effect of commitment, on employee performance at the North Sumatra I DGT Regional Office? How does the influence of employee behavior on employee performance? How does the influence of employee work ability on employee performance? How does the influence of supervision on employee performance? How big is the influence of commitment, employee behavior, work ability and supervision on employee performance at the North Sumatra I DGT Regional Office?. The purpose of this research is: To analyze and determine the effect of commitment to employee performance partially, to determine the effect of employee behavior on employee performance partially, to determine the effect of employee ability to work partially on employee performance, to determine the effect of partial supervision on employee performance, to know the effect of commitment, employee behavior and supervision of employee performance at the North Sumatra DGT Regional Office I. Data analysis technique used is multiple linear regression analysis.

The results showed that there was a significant influence between commitment to employee performance, because according to the results of the analysis of t count $>t$-table (3.107> 1.67) at $n$ $=76$ with a significance level of $95 \%$, there was a significant effect between employee behavior on performance employees, because according to the results of $t$ analysis $>t$-table (5.306> 1.67) at $n$ $=76$ with a significance level of 95\%, there is a significant influence between work ability on employee performance, because according to the results of t analysis $>t$-table $(2,161>1.65)$ at $n=$ 76 with a significance level of 95\%, There is a significant influence between supervision on employee performance, because according to the results of t analysis $>t$-table $(3,434>1.67)$ at $n=$ 76 with a level significant $95 \%$, $F$-count value $>F$ table (17.950> 2.72) together (multiple) there is a positive and significant effect of commitment, employee behavior, supervision, the performance of large employees influence by $28.8 \%$. Thus the hypothesis proposed is accepted.
\end{abstract}

Keyword : commitment, employee behavior, work ability, supervision and employee performance.

ABSTRAK : Rumusan masalah dalam penelitian ini adalah : Bagaimana pengaruh komitmen, terhadap kinerja pegawai pada Kantor Wilayah DJP Sumatera Utara I? Bagaimana pengaruh perilaku pegawai terhadap kinerja pegawai?, Bagaimana pengaruh kemampuan kerja pegawai terhadap kinerja pegawai?, Bagaimana pengaruh pengawasan terhadap kinerja pegawai?, Seberapa besar pengaruh komitmen, perilaku pegawai, kemampuan kerja dan pengawasan terhadap kinerja pegawai pada Kantor Wilayah DJP Sumatera Utara I ?. Tujuan Penelitiaan Adalah : Untuk menganalisis dan mengetahui pengaruh komitmen terhadap kinerja pegawai secara parsial, untuk mengetahui pengaruh perilaku pegawai terhadap kinerja pegawai secara parsial, untuk mengetahui pengaruh kemampuan kerja pegawai secara parsial terhadap kinerja pegawai, untuk mengetahui pengaruh pengawasan secara parsial terhadap kinerja pegawai, untuk mengetahui pengaruh komitmen, perilaku pegawai dan pengawasan terhadap kinerja pegawai pada Kantor Wilayah DJP Sumatera Utara I. Teknik analisis data yang digunakan adalah analisis regresi linier berganda. Hasil penelitian diperoleh bahwa Ada pengaruh yang signifikan antara komitmen terhadap kinerja pegawai, karena menurut hasil analisis thitung > t-tabel $(3,107>1,67)$ pada $n=76$ dengan taraf sigifikansi 95\%, Ada pengaruh yang signifikan antara perilaku pegawai terhadap kinerja pegawai, karena menurut hasil analisis thitung $>t$-tabel $(5,306>1,67)$ pada $n=$ 76 dengan taraf signifikansi 95\%, Ada pengaruh yang signifikan antara kemampuan kerja 
terhadap kinerja pegawai, karena menurut hasil analisis thitung $>t$-tabel $(2,161>1,65)$ pada $n=$ 76 dengan taraf signifikan 95\%,Ada pengaruh yang signifikan antara pengawasan terhadap kinerja pegawai, karena menurut hasil analisis thitung > t-tabel $(3,434>1,67)$ pada $n=76$ dengan taraf signifikan 95\%,Nilai F-hitung > F tabel (17,950 > 2,72) secara bersama-sama (multiple) terdapat pengaruh positif dan signifikan komitmen,perilaku poegawai, pengawasan, terhadap kinerja pegawai besar pengaruhnya sebesar 28,8\%. Dengan demikian hipotesis yang diajukan diterima kebenarannya.

Keyworld : komitmen, perilaku pegawai, kemampuan kerja, pengawasan dan kinerja pegawai.

\section{Pendahuluan}

Kinerja dalam suatu organisasi apapun sangat penting, apabila pegawai tidak memiliki kinerja maka organisasi tidak akan baik. Kinerja pegawai merupakan pusat perhatian pimpinan. Banyak faktor yang mempengaruhi kinerja seperti motivasi, komitmen, perilaku, pengawasan, pendidikan dan lain-lain. Komitmen pegawai terhadap organisasi sangat diperlukan untuk menciptakan iklim kerja yang profesional. Komitmen dapat diartikan sebagai sikap pegawai untuk tetap berada dalam organisasi dan terlibat dalam upaya-upaya mencapai misi, nilai-nilai dan tujuan organisasi. Komitmen individu terhadap organisasi ini dipandang penting karena pegawai yang memiliki komitmen yang tinggi terhadap organisasi akan memiliki sikap yang profesional dan menjunjung tinggi nilai-nilai yang telah disepakati dalam organisasi.

Untuk membangun komitmen individu terhadap organisasi dapat dilakukan melalui pendekatan lunak dan pendekatan keras. Pendekatan lunak dilakukan dengan menumbuhkan motivasi kerja pegawai. Hal ini dilakukan dengan cara melibatkan mereka dalam proses pengambilan keputusan dan membangun kultur organisasi yang berbasis teamwork dan kepercayaan. Ekspansi keterlibatan pegawai dalam pengambilan keputusan adalah inti dari rencana komitmen. Selanjutnya pendekatan keras yang dilakukan berkaitan dengan 3 faktor yang saling berkaitan yakni :system rekruitmen dan seleksi, system pelatihan, system pengembangan.

Selanjutnya perilaku pegawai turut menentukan kinerja pegawai, oleh sebab itu pimpinan harus mampu mengendalikan pegawai. Mengendalikan maksudnya adalah mengarahkan perilaku pegawai kepada orientasi kelompok, yang pada gilirannya berkembang menjadi perilaku organisasional. Pengarahan yang demikian tidak mudah, terutama dalam organisasi yang besar dimana hubungan langsung yang bersifat individual antara pimpinan dan para bawahannya tidak selalu mungkin. Paling tidak, tidak mungkin untuk dilakukan setiap hari. Akan tetapi meskipun pengarahan itu tidak mudah, setiap pimpinan harus melakukannya. Kegagalan melakukan hal ini akan berakibat tidak tercapainya tujuan organisasi, yang apabila terjadi akan berarti tidak tercapainya tujuan-tujuan pribadi daripada para anggota organsiasi yang bersangkutan. Perilaku pegawai didasarkan pada perilaku organisasi dimana perilaku organisasi merupakan norma-norma dan nilai-nilai yang mengarahkan perilaku anggota organisasi. Setiap anggota akan berprilaku sesuai dengan budaya yang berlaku.

Pimpinan harus berupaya meningkatkan komitmen pegawai dan meningkatkan perilaku pegawai terhadap misi dan tujuan organisasi, dengan melalui eksistensi pegawai sebagai sumber kekuatan kunci daya saing dan sumber kekuatan menerobos persaingan. Kepribadian organisasi ini dikembangkan berdasarkan teori individual personality yakni keseimbangan antara cara individu melihat dirinya, cara individu ingin dilihat dan cara individu dilihat orang lain. Semakin harmonis hubungan ketiga hal tersebut semakin kuat kepribadian seseorang. Adanya kepribadian yang kuat tersebut akan melangkah kedepan dengan pasti dengan keyakinan orang lain akan menerima kehadirannya dan memberikan kepercayaan kepadanya.

Hal ini berarti bagaimana mengajak pegawai bekerjasama dalam kesatuan cara berpikir atau semangat mencapai tujuan dan arah organisasi.Kekuatanorganisasi yang berfokus pada company personality, bersandar pada keseimbangan tiga kondisi yaitu dengan a). Cara organisasi melihatdirinya, mendorong organisasi untuk selalu melihat kekuatan dan kelemahan faktor-faktor internal organisasi sepertifaktor kultur dan factor Sumber Daya Manusia yang dimiliki, b). Cara organisasi ingin melihat seperti apa di masa yang akan dating akan mendorong organisasi menjalankan kegiatannya berdasarkan misi yang jelas, c) 
Cara pasar melihat organisasi, menunjukkan posisi organisasi secara eksternal.

Keseimbangan ketiga kondisi ini merupakan sumber kekuatan organisasi karena organisasi yang memiliki keseimbangan itu adalah organisasi yang selalu meletakkan keseimbangan antara kepentingan internal dan kepentingan dunia luar. Jembatannya adalah kekuatan Sumber Daya Manusia sebagai elemen kunci dalam keberhasilan menjalankan misinya. Pimpinan harus mempunyai prinsip bagaimana orang-orang dalam organisasi diperlakukan terutama dalam hal yang bersangkutan dengan keahlian, serta memiliki kemampuan kerja yang tinggi,kompetensi dan aspek-aspek lain yang dilakukanatasnamaorganisasi yang berorientasi kepada kinerja.

Hal lain yang dapat merangsang pegawai agar memiliki kinerja baik adalah pengawasan. Tanpa ada pengawasan dilakukan sulit memperoleh kinerja pegawai yang tinggi. Karena tanpa ada pengawasan pegawai banyak yang bekerja kurang serius dan pimpinan tidak mengetahui apa kelemahan dan kekurangan pegawai. Pengawasan akan mengarahkan individu untuk tetap bekerja sesuai dengan aturan yang telah ditetapkan. Pengawasan juga diperlukan agar organisasi tetap berada pada jalur yang benar dan dipimpin oleh individu yang tepat. Selain itu, setiap manusia memiliki kecenderungan untuk bekerja serius ketika diawasi dan akan melemah ketika tidak diawasi. Dengan demikian, pengawasan juga memiliki peran agar prestasi kerja pegawai dapat tercapai sebagaimana yang diharapkan. Dalam kenyataannya, menegakkan sistem pengawasan yang efektif tidaklah mudah. Terlalu fleksibel dalam menjalankan pengawasan akan melemahkan wibawa organisasi di hadapan stakeholder. Sebaliknya, terlalu ketat dalam menjalankan pengawasan akan menurunkan kreativitas kerja para pegawai. Pegawai atau individu akan merasakan suasana kerja yang monoton dan membosankan. Pada gilirannya, hal ini akan menimbukan kelelahan mental (burn out) yang jika tidak ditangani dengan serius akan menimbulkan demotivasi dan penurunan prestasi kerja. Tanpa pengawasan sulit untuk memastikan bahwa tujuan organisasi akan dicapai karena organisasi tidak mampu mendeteksi gejala-gejala penyimpangan terhadap tujuan. Jika hal ini dibiarkan, maka organisasi akan kehilangan kesempatan untuk memperbaiki dan memperoleh prestasi kerja pegawai sehingga sulit untuk menggapai kinerja.

Kinerja pegawai dipengaruhi beberapa faktor dan termasuk empat faktor yang disebutkan di atas. Dengan demikian dapat disebutkan bahwa komitmen, perilaku pegawai, kemampuan kerja dan pegawasan dapat berpengaruh terhadap kinerja pegawai.

Komitmen pegawai di Kantor Wilayah DJP Sumatera Utara I masih rendah, dimana pegawai masih memiliki sikap yang kurang profesional dan kurang menjunjung tinggi nilainilai yang telah disepakati dalam organisasi. Selain itu pegawai jarang sekali ikut dilibatkan dalam proses pengambilan keputusan dan membangun kultur organisasi yang berbasis teamwork dan kepercayaan. Ekspansi keterlibatan pegawai dalam pengambilan keputusan sebagaimana disebutkan di atas adalah inti dari rencana komitmen.

Perilaku pegawai di Kantor Wilayah DJP Sumatera Utara I Utara juga masih jauh dari harapan, artinya masih sulit mengarahkan perilaku pegawai kepada orientasi kelompok. Hal ini pegawai masih tidak memperdulikan budaya organisasi dan perilaku organisasional. Pimpinan juga kurang memberi pengarahan sehingga berakibat tidak tercapainya tujuan organisasi. Perilaku pegawai masih didasarkan pada perilaku individual dan perilaku lain yang merupakan norma-norma dan nilai-nilai yang mengarahkan perilaku anggota organisasi. Setiap anggota akan berprilaku sesuai dengan budaya yang ada di luarorganisasibukanbudaya yang adadalamorganisasi. Kurangnya kompetensi dan rendahnya perilaku pegawai sehingga kemampuan kerja pegawai yang rendah yang berakibat rendahnya kinerja pegawai

Pengawasan terhadap pegawai dan pekerjaan pegawai masih kurang dilakukan Karena kurangnya pengawasan pegawai banyak yang bekerja kurang serius dan pimpinan tidak mengetahui apa kelemahan dan kekurangan pegawai. Pengawasan akan mengarahkan individu untuk tetap bekerja sesuai dengan aturan yang telah ditetapkan. Pengawasan juga diperlukan agar organisasi tetap berada pada jalur yang benar dan dipimpin oleh individu yang tepat

Adapun tujuan penelitian yang penulis buat adalah sebagai berikut :

1. Untuk menganalisis pengaruh komitmen terhadap kinerja pegawai pada Kantor Wilayah DJP Sumatera Utara I 
2. Untuk menganalisis pengaruh perilaku pegawai terhadap kinerja pegawai pada Kantor Wilayah DJP Sumatera Utara I

3. Untuk menganalisis pengaruh kemampuan kerja terhadap kinerja pegawai pada Kantor Wilayah DJP Sumatera Utara I

4. Untuk menganalisis pengaruh pengawasan terhadap kinerja pegawai pada Kantor Wilayah DJP Sumatera Utara I

5. Untuk menganalisis pengaruh komitmen, perilaku pegawai, kemampuan kerja dan pengawasan terhadap kinerja pegawai pada Kantor Wilayah DJP Sumatera Utara I

\section{Metode Penelitian}

\subsection{Populasi dan Sampel}

Sugiyono (2010: 90) mengemukakan: "Populasi adalah wilayah generalisasi yang terdiri atas objek/subjek yang mempunyai kualitas dan karakteritik tertentu yang ditetapkan oleh peneliti. Berdasarkan pengertian ini populasi bisa berupa semua individu yang mewakili pola kelakuan tertentu atau sebahagian dari kelompok itu ". Artinya populasi dapat berupa individu yang mewakili pola kelakuan atau sebagian. Populasi penelitian ini adalah semua pegawai di Kantor Wilayah DJP Sumatera Utara I yang berjumlah Populasi penelitian ini adalah semua pegawai di Kantor Wilayah DJP Sumatera Utara I berjumlah 126 orang.

Sampel penelitian ditetapkan berdasarkan ketentuan Arikunto, (2010:120) yaitu : Apabila populasi kurang dari 100 orang, lebih baik diambil semua sehingga penelitian merupakan penelitian populasi. Jika jumlah subjeknya lebih dari 100 orang, dapat diambil $10-15 \%$ atau 20 - $25 \%$ atau lebih." Disebabkan populasi lebih 100 orang maka sampel penelitian ditetapkan sebesar $60 \%$ (76 orang)

\subsection{Pengujian Validitas}

Uji validitas dilakukan terhadap isi dari suatu instrumen, tujuan dilakukannya pengujian ini adalah untuk mengukur ketetapan instrumen yang digunakan. Untuk pengujian validitas ini dilakukan dengan menggunakan koefisien korelasi Product Moment. Item kuesioner dikatakan valid apabila nilai $r_{\text {hitung }}>r_{\text {tabel }}$. Uji validitas pada penelitian ini dapat dilihat pada table berikut :

Table 1

Uji Validitas variable $\mathrm{X}_{1}$

\begin{tabular}{|c|c|c|c|c|}
\hline Pertanyaan & $\begin{array}{c}\text { Nilai } \\
\text { Korelasi }(\mathbf{r})\end{array}$ & $\begin{array}{c}\mathbf{r} \text {-tabel } \\
(\mathbf{n}=76)\end{array}$ & Keterangan & Kesimpulan \\
\hline 1 & 0.619 & 0,228 & $\mathrm{r}_{\text {hitung }}>\mathrm{r}_{\text {tabel }}$ & Valid \\
\hline 2 & 0.530 & 0,228 & $\mathrm{r}_{\text {hitung }}>\mathrm{r}_{\text {tabel }}$ & Valid \\
\hline 3 & 0.694 & 0,228 & $\mathrm{r}_{\text {hitung }}>\mathrm{r}_{\text {tabel }}$ & Valid \\
\hline 4 & 0.702 & 0,228 & $\mathrm{r}_{\text {hitung }}>\mathrm{r}_{\text {tabel }}$ & Valid \\
\hline 5 & 0.679 & 0,228 & $\mathrm{r}_{\text {hitung }}>\mathrm{r}_{\text {tabel }}$ & Valid \\
\hline 6 & 0.699 & 0,228 & $\mathrm{r}_{\text {hitung }}>\mathrm{r}_{\text {tabel }}$ & Valid \\
\hline 7 & 0.718 & 0,228 & $\mathrm{r}_{\text {hitung }}>\mathrm{r}_{\text {tabel }}$ & Valid \\
\hline 8 & 0.413 & 0,228 & $\mathrm{r}_{\text {hitung }}>\mathrm{r}_{\text {tabel }}$ & Valid \\
\hline 9 & 0.775 & 0,228 & $\mathrm{r}_{\text {hitung }}>\mathrm{r}_{\text {tabel }}$ & Valid \\
\hline 10 & 0.468 & 0,228 & $\mathrm{r}_{\text {hitung }}>\mathrm{r}_{\text {tabel }}$ & Valid \\
\hline
\end{tabular}

Table 2

Uji Validitas variable $\mathrm{X}_{2}$

\begin{tabular}{|c|c|c|c|c|}
\hline Pertanyaan & $\begin{array}{c}\text { Nilai } \\
\text { Korelasi (r) }\end{array}$ & $\begin{array}{c}\mathbf{r} \text {-tabel } \\
(\mathbf{n}=\mathbf{7 6})\end{array}$ & Keterangan & Kesimpulan \\
\hline 1 & 0.766 & 0,228 & $\mathrm{r}_{\text {hitung }}>\mathrm{r}_{\text {tabel }}$ & Valid \\
\hline 2 & 0.785 & 0,228 & $\mathrm{r}_{\text {hitung }}>\mathrm{r}_{\text {tabel }}$ & Valid \\
\hline 3 & 0.510 & 0,228 & $\mathrm{r}_{\text {hitung }}>\mathrm{r}_{\text {tabel }}$ & Valid \\
\hline 4 & 0.603 & 0,228 & $\mathrm{r}_{\text {hitung }}>\mathrm{r}_{\text {tabel }}$ & Valid \\
\hline 5 & 0.386 & 0,228 & $\mathrm{r}_{\text {hitung }}>\mathrm{r}_{\text {tabel }}$ & Valid \\
\hline 6 & 0.601 & 0,228 & $\mathrm{r}_{\text {hitung }}>\mathrm{r}_{\text {tabel }}$ & Valid \\
\hline 7 & 0.354 & 0,228 & $\mathrm{r}_{\text {hitung }}>\mathrm{r}_{\text {tabel }}$ & Valid \\
\hline
\end{tabular}




\begin{tabular}{|c|c|c|c|c|}
\hline Pertanyaan & $\begin{array}{c}\text { Nilai } \\
\text { Korelasi }(\mathbf{r})\end{array}$ & $\begin{array}{c}\mathbf{r} \text {-tabel } \\
(\mathbf{n = 7 6 )}\end{array}$ & Keterangan & Kesimpulan \\
\hline 8 & 0.511 & 0,228 & $\mathrm{r}_{\text {hitung }}>\mathrm{r}_{\text {tabel }}$ & Valid \\
\hline 9 & 0.765 & 0,228 & $\mathrm{r}_{\text {hitung }}>\mathrm{r}_{\text {tabel }}$ & Valid \\
\hline 10 & 0.765 & 0,228 & $\mathrm{r}_{\text {hitung }}>\mathrm{r}_{\text {tabel }}$ & Valid \\
\hline
\end{tabular}

Sumber : Hasil pengolahan Data, 2019

Table 3

Uji Validitas variable $\mathrm{X}_{3}$

\begin{tabular}{|c|c|c|l|c|}
\hline Pertanyaan & $\begin{array}{c}\text { Nilai } \\
\text { Korelasi }(\mathbf{r})\end{array}$ & $\begin{array}{c}\mathbf{r} \text {-tabel } \\
(\mathbf{n}=76)\end{array}$ & Keterangan & Kesimpulan \\
\hline 1 & 0,772 & 0,228 & $\mathrm{r}_{\text {hitung }}>\mathrm{r}_{\text {tabel }}$ & Valid \\
\hline 2 & 0,789 & 0,228 & $\mathrm{r}_{\text {hitung }}>\mathrm{r}_{\text {tabel }}$ & Valid \\
\hline 3 & 0,510 & 0,228 & $\mathrm{r}_{\text {hitung }}>\mathrm{r}_{\text {tabel }}$ & Valid \\
\hline 4 & 0,602 & 0,228 & $\mathrm{r}_{\text {hitung }}>\mathrm{r}_{\text {tabel }}$ & Valid \\
\hline 5 & 0,375 & 0,228 & $\mathrm{r}_{\text {hitung }}>\mathrm{r}_{\text {tabel }}$ & Valid \\
\hline 6 & 0,603 & 0,228 & $\mathrm{r}_{\text {hitung }}>\mathrm{r}_{\text {tabel }}$ & Valid \\
\hline 7 & 0,509 & 0,228 & $\mathrm{r}_{\text {hitung }}>\mathrm{r}_{\text {tabel }}$ & Valid \\
\hline 8 & 0,512 & 0,228 & $\mathrm{r}_{\text {hitung }}>\mathrm{r}_{\text {tabel }}$ & Valid \\
\hline 9 & 0,771 & 0,228 & $\mathrm{r}_{\text {hitung }}>\mathrm{r}_{\text {tabel }}$ & Valid \\
\hline 10 & 0,770 & 0,228 & $\mathrm{r}_{\text {hitung }}>\mathrm{r}_{\text {tabel }}$ & Valid \\
\hline
\end{tabular}

Sumber : Hasil pengolahan Data, 2019

Table 4

Uji Validitas variable $\mathrm{X}_{4}$

\begin{tabular}{|c|c|c|c|c|}
\hline Pertanyaan & $\begin{array}{c}\text { Nilai } \\
\text { Korelasi }(\mathbf{r})\end{array}$ & $\begin{array}{c}\text { r-tabel } \\
(\mathbf{n}=76)\end{array}$ & Keterangan & Kesimpulan \\
\hline 1 & 0.604 & 0,228 & $\mathrm{r}_{\text {hitung }}>\mathrm{r}_{\text {tabel }}$ & Valid \\
\hline 2 & 0.700 & 0,228 & $\mathrm{r}_{\text {hitung }}>\mathrm{r}_{\text {tabel }}$ & Valid \\
\hline 3 & 0.750 & 0,228 & $\mathrm{r}_{\text {hitung }}>\mathrm{r}_{\text {tabel }}$ & Valid \\
\hline 4 & 0.835 & 0,228 & $\mathrm{r}_{\text {hitung }}>\mathrm{r}_{\text {tabel }}$ & Valid \\
\hline 5 & 0.788 & 0,228 & $\mathrm{r}_{\text {hitung }}>\mathrm{r}_{\text {tabel }}$ & Valid \\
\hline 6 & 0.718 & 0,228 & $\mathrm{r}_{\text {hitung }}>\mathrm{r}_{\text {tabel }}$ & Valid \\
\hline 7 & 0.710 & 0,228 & $\mathrm{r}_{\text {hitung }}>\mathrm{r}_{\text {tabel }}$ & Valid \\
\hline 8 & 0.602 & 0,228 & $\mathrm{r}_{\text {hitung }}>\mathrm{r}_{\text {tabel }}$ & Valid \\
\hline 9 & 0.584 & 0,228 & $\mathrm{r}_{\text {hitung }}>\mathrm{r}_{\text {tabel }}$ & Valid \\
\hline 10 & 0.629 & 0,228 & $\mathrm{r}_{\text {hitung }}>\mathrm{r}_{\text {tabel }}$ & Valid \\
\hline
\end{tabular}

Sumber : Hasil pengolahan Data, 2019

Table 5

Uji Validitas variable $\mathrm{Y}$

\begin{tabular}{|c|c|c|c|c|}
\hline Pertanyaan & $\begin{array}{c}\text { Nilai } \\
\text { Korelasi }(\mathbf{r})\end{array}$ & $\begin{array}{c}\mathbf{r} \text {-tabel } \\
(\mathbf{n}=76)\end{array}$ & Keterangan & Kesimpulan \\
\hline 1 & 0.558 & 0,228 & $\mathrm{r}_{\text {hitung }}>\mathrm{r}_{\text {tabel }}$ & Valid \\
\hline 2 & 0.470 & 0,228 & $\mathrm{r}_{\text {hitung }}>\mathrm{r}_{\text {tabel }}$ & Valid \\
\hline 3 & 0.693 & 0,228 & $\mathrm{r}_{\text {hitung }}>\mathrm{r}_{\text {tabel }}$ & Valid \\
\hline 4 & 0.665 & 0,228 & $\mathrm{r}_{\text {hitung }}>\mathrm{r}_{\text {tabel }}$ & Valid \\
\hline 5 & 0.608 & 0,228 & $\mathrm{r}_{\text {hitung }}>\mathrm{r}_{\text {tabel }}$ & Valid \\
\hline 6 & 0.606 & 0,228 & $\mathrm{r}_{\text {hitung }}>\mathrm{r}_{\text {tabel }}$ & Valid \\
\hline 7 & 0.634 & 0,228 & $\mathrm{r}_{\text {hitung }}>\mathrm{r}_{\text {tabel }}$ & Valid \\
\hline 8 & 0.761 & 0,228 & $\mathrm{r}_{\text {hitung }}>\mathrm{r}_{\text {tabel }}$ & Valid \\
\hline 9 & 0.384 & 0,228 & $\mathrm{r}_{\text {hitung }}>\mathrm{r}_{\text {tabel }}$ & Valid \\
\hline 10 & 0.519 & 0,228 & $\mathrm{r}_{\text {hitung }}>\mathrm{r}_{\text {tabel }}$ & Valid \\
\hline
\end{tabular}

Sumber : Hasil pengolahan Data, 2019 
Pada Tabel diatas dapat diperoleh nilai korelasi semua variabel lebih besar dari 0,228. Hal ini menunjukkan bahwa semua item pertanyaan masing-masing variabel adalah valid.

\subsection{Analisis Regresi Linear Berganda}

Analisis regresi digunakan untuk menganalisis data hasil penelitian dengan maksud untuk memperoleh gambaran hubungan fungsional antara variabel bebas dengan variabel terikat hal ini dengan menggunakan analisis regresi linier berganda.

Tabel 6

Koefisien Regresi

\begin{tabular}{|c|c|c|c|c|c|c|}
\hline & \multirow[t]{2}{*}{ Model } & \multicolumn{2}{|c|}{$\begin{array}{c}\text { Unstandardized } \\
\text { Coefficients }\end{array}$} & $\begin{array}{r}\text { Standardized } \\
\text { Coefficients } \\
\end{array}$ & \multirow[t]{2}{*}{ t. } & \multirow[t]{2}{*}{ Sig. } \\
\hline & & B & Std. Error & Beta & & \\
\hline \multirow{5}{*}{1} & (Constant) & 18,010 &, 895 & & 20,118 & ,000 \\
\hline & Komitmen & ,132 & ,043 & 251 & 3,107 & ,003 \\
\hline & Perilaku Pegawai & ,209 & ,039 & ,363 & 5,306 & ,000 \\
\hline & Kemampuan kerja & ,073 & ,034 & 159 & 2,161 & ,034 \\
\hline & Pengawasan & , 160 & 047 & 263 & 3,434 & 001 \\
\hline
\end{tabular}

Sumber : Hasil Pengolahan Data, 2019

Berdasarkan Tabel diatas diperoleh koefisien regresi variabel Komitmen 0,132, Perilaku pegawai $=0,209$, kemampuan kerja 0,073 , Pengawasan 0,160 dengan konstanta 18,010, maka dapat dituliskan persamaan regresi sebagai berikut.

$$
\begin{aligned}
& Y=18,010+0,132 X_{1}+0,209 X_{2}+0,073 X_{3}+ \\
& 0,160 X_{4}
\end{aligned}
$$

Persamaan di atas menunjukkan konstanta bernilai positip dan nilai koefisien regresi juga positip. Hal ini memberi gambaran bahwa perubahan rata-rata variabel Kinerja Pegawai (Y) tergantung dari perubahan variabel Tabel 7

Komitmen $\left(\mathrm{X}_{1}\right)$, Perilaku pegawai $\left(\mathrm{X}_{2}\right)$. kemempuan kerja $\left(\mathrm{X}_{3}\right)$ dan Pengawasan $\left(\mathrm{X}_{4}\right)$. Artinya apabila komitmen, Perilaku Pegawai, kemampuan kerja,Pengawasan ditingkatkan akan diikuti perubahan/peningkatan Kinerja Pegawai. Perubahan ini merupakan peningkatan apabila bertanda positip dan penurunan atau pengurangan jika bertanda negatif. Hal ini menunjukkan bahwa ada pengaruh Motivasi, Perilaku Pegawai Pengawasan terhadap Kinerja pegawai.

\subsection{Uji Signifikan Simultan (Uji F)}

Uji F (Uji Simultan)

ANOVA

\begin{tabular}{|rl|r|r|r|r|r|}
\hline \multicolumn{2}{|r|}{ Model } & \multicolumn{1}{|c|}{$\begin{array}{c}\text { Sum of } \\
\text { Squares }\end{array}$} & \multicolumn{1}{c|}{ df } & \multicolumn{1}{c|}{$\begin{array}{l}\text { Mean } \\
\text { Square }\end{array}$} & F & Sig. \\
\hline \multirow{2}{*}{1} & Regression & 111,947 & 4 & 27,987 & 124,289 &, $000^{\mathrm{b}}$ \\
& Residual & 15,987 & 71 &, 225 & & \\
& Total & 127,934 & 75 & & & \\
\hline
\end{tabular}

a. Dependent Variable: kinerja pegawai

b. Predictors: (Constant), Pengawasan, Perilaku Pegawai, Kemampuan kerja, Komitmen

Berdasarkan tabel di atas diketahui nilai Fhitung sebesar 124,289 sedangkan nilai F-tabel dengan dk pembilang $4 \mathrm{dan} \mathrm{dk}$ penyebut 72 adalah sebesar 2,50 dimana F-hitung > F tabel $(124,289>2,50)$ maka dapat disebutkan bahwa secara bersama-sama (simultan) terdapat pengaruh positif dan signifikan komitmen, Perilaku, kemampuan kerjadan Pengawasan terhadap Kinerja Pegawai.

\subsection{Uji Signifikan Parsial (t)}

Untuk mengetahui pengaruh variabel bebas secara parsial terhadap variabel terikat digunakan uji t, dimana dengan ketentuan :

a. $\mathrm{t}$ - hitung $\leq \mathrm{t}$ - tabel (tidak ada pengaruh variabel bebas secara tersendiri terhadap variabel terikat)

b. t- hitung > t- tabel (ada pengaruh variabel bebas secara tersendiri terhadap variabel terikat)

c. derajat kebebasan $(\mathrm{dk})=\mathrm{n}-4$ dan Tingkat kepercayaan $\alpha=0,05$. 
Tabel 8

Uji Parsial (Uji t)

\begin{tabular}{|c|c|c|c|c|c|c|}
\hline & \multirow[t]{2}{*}{ Model } & \multicolumn{2}{|c|}{$\begin{array}{c}\text { Unstandardized } \\
\text { Coefficients }\end{array}$} & \multirow{2}{*}{$\begin{array}{l}\text { Standardized } \\
\text { Coefficients } \\
\text { Beta }\end{array}$} & \multirow[t]{2}{*}{ t. } & \multirow[t]{2}{*}{ Sig. } \\
\hline & & $\mathrm{B}$ & Std. Error & & & \\
\hline \multirow{5}{*}{1} & (Constant) & 18,010 &, 895 & & 20,118 & ,000 \\
\hline & Komitmen &, 132 & 043 & ,251 & 3,107 & 003 \\
\hline & Perilaku Pegawai & ,209 & ,039 & ,363 & 5,306 &, 000 \\
\hline & Kemampuan kerja & ,073 & 034 & 159 & 2,161 & 034 \\
\hline & Pengawasan & , 160 & 047 & ,263 & 3,434 & 001 \\
\hline
\end{tabular}

Berdasarkan tabel 8. di atas diperoleh

1. Nilai $t_{\text {hitung }}$ komitmen $=3,107$, sedangkan $t$ tabel dengan $\mathrm{dk} 56$ sebesar 1,99 maka thitung > t-tabel dengan demikian secara parsial ada pengaruh yang signifikan antara Kompetensi Pegawai terhadap pengembangan pegawai.

2. Nilai $t_{\text {hitung }}$ perilaku pegawai $=5,306$, sedangkan t-tabel dengan dk 56 sebesar 1,99 maka $\mathrm{t}$ hitung $>\mathrm{t}$ tabel dengan demikian secara parsial ada pengaruh yang signifikan antara etos kerja terhadap pengembangan pegawai.

3. Nilai $t_{\text {hitung }}$ kemampuan kerja $=2,161$, sedangkan t-tabel dengan dk 56 sebesar 1,99 maka $\mathrm{t}$ hitung $>\mathrm{t}$ tabel dengan demikian secara parsial ada pengaruh yang signifikan

Tabel 9

Koefisien Determinasi

Model Summary

\begin{tabular}{|l|r|r|r|r|}
\hline Model & R & R Square & Adjusted R Square & Std. Error of the Estimate \\
\hline 1 &, $935^{\mathrm{a}}$ &, 875 &, 868 &, 47453 \\
\hline
\end{tabular}

Sumber; Pengolahan data, 2019

Berdasarkan table diatas diperoleh $\mathrm{R}^{2}=$ 0,875 maka $\mathrm{D}=0,875 \times 100 \%$ sehingga $\mathrm{D}=$ $87,5 \%$. Dengan demikian pengaruh komitmen, Perilaku pegawai, kemampuan kerjadan Pengawasan terhadap Kinerja Pegawai sebesar $87,5 \%$. sedangkan $12,5 \%$ lagi yang mempengaruhi Kinerja Pegawai ditentukan faktor lain yang tidak diteliti dalam penelitian ini.

\section{Kesimpulan}

Berdasarkan pada analisis dan evaluasi data di atas, maka kesimpulan dari penelitian ini adalah :

1. Variabel komitmen berpengaruh positif dan signifikan terhadap kinerja pegawai, dengan nilai thitung > t-tabel $(3,107>1,67)$ antara Fasilitas Kerja terhadap pengembangan pegawai.

4. Nilai $t_{\text {hitung }}$ pengawasan $=3,434$, sedangkan t-tabel dengan dk 56 sebesar 1,99 maka t hitung $>\mathrm{t}$ tabel dengan demikian secara parsial ada pengaruh yang signifikan antara Disiplin Kerja terhadap pengembangan

\subsection{Uji Determinasi (R Square)}

2. Variabel perilaku pegawai berpengaruh positif dan signifikan terhadap kinerja pegawai dengan nilai thitung $>\mathrm{t}$-tabel $(5,306$ $>1,67)$

3. Variabel kemampuan kerja berpengaruh positif dan signifikan terhadap kinerja pegawai dengan thitung > t-tabel $(2,161>$ $1,65)$

4. Variabel pengawasan berpengaruh positif dan signifikan terhadap kinerja pegawai dengan thitung $>$ t-tabel $(3,434>1,67)$

5. Nilai F-hitung > F tabel $(17,950>2,72)$ secara bersama-sama (simultan) variabel komitmen, perilaku pegawai, kemampuan kerja dan pengawasan berpengaruh signifikan terhadap kinerja pegawai sebesar $28,8 \%$. pegawai. 


\section{DAFTAR PUSTAKA}

Alwi, Syafaruddin, (2009), Alat-Alat Analisis dalam Pembelanjaan, Yogyakarta, Andi Offset.

Djinarto Bambang, (2009), Perencanaan, Trategi, dan Pengawasan Manajemen, Jakarta, PT. Gramedia Pustaka Utama.

Dwiyanto, Agus, (2012), Penilaian Kinerja organisasi Pelayanan Publik, UGM, Yogyakarta.

Gibson, I \& Donnelly, (2011), Organizations, Behavior, Structure, Processes, 9 Ed. Richard D. Irwin Inc.

Gie, The Liang, (2011), Administrasi Perkantoran Modern, Yogyakarta:Liberty,

Handayaningrat, Soewarno, (2011). Pengantar Administrasi dan Manajemen, Jakarta, Penerbit PT. Gunung Agung

Handoko, T. Hani, (2009), Manajemen Personalia dan Sumber Daya Manusia, Cetakan pertama, Jakarta, Liberti,.

Kreitner Robert, (2009), Organizational Behavior, (Perilaku Organisasi), Terjemahan Erly Suandy, Penerbit Salemba Empat, Jakarta.

Komaruddin, (2012), Ensiklopedia Manajemen, Bandung, Alumni,

Mahmudi, (2012), Manajemen Kinerja Sektor Publik, Akademi Manajemen, Jakarta, Perusahaan YKPN.

Mangkunegara. (2009). Evaluasi Kinerja SDM. Bandung, PT. Refika Aditama,.

Mathias, Robert, dan Jackson, John, (2012), Manajemen Sumber Daya Manusia, Terjemahan Jimmy Sadili dan Bayu Prawira, Jakarta : Penerbit Salemba Empat.

Nitisemito, Alex S, (2009). Manajemen Personalia Jakarta, Ghalia Indonesia, :

Pramono,Cahyo (2012). Pengawasan. Waspada Online (www.waspada.co.id)

Rivai, Veithzal, (2015), Performance Appraisal, Jakarta, PT. RajaGrafindo Persada,

Robbins, Stephen P. (2010). Perilaku Organisasi. Jakarta,PT. Indeks,

Saefullah , (2018), Manajemen Personalia, Yogyakarta,BPFE, Gajah Mada

Sarwoto, (2009), Dasar-Dasar Organisasi dan Manajemen, Jakarta, Gunung Agung, :

Siagian, Sondang, P. (2010),.Organisasi, Kepemimpinan dan Prilaku Organisasi, Jakarta,Gunung Agung,
Sinungan Muchdarsyah,(2012), Produktivitas Apa dan Bagaimana, Jakarta, Bumi Aksara

Sedarmayanti, (2011), Sumber Daya Manudia dan produktivitas Kerja, Bandung, Ilham Jaya,

Sudarmono, Indriyono Gito, (2010), Sistem Perencanaan dan Pengawasan Manajemen, Jakarta, Revisi, Salemba Empat

Sugiyono, (2010), Metode Penelitian Administrasi, Bandung, Alfabeta,

Suma'mur, (2011), Evaluasi Kinerja SDM, Bandung : Refika Aditama

Suprianto, J. (2013), Metode Riset Aplikasi dan Pemasaran, : UI, FE.

Soesmanto, Bintang (2009). Pengawasan Intern Pada Menko Kesra. (www.menkokesra.com)

Tangkilisan, Hessel Hogi S, (2011), Manajemen Publik, Jakarta, Grasindo,

Wijaya Tony, (2011), Cepar Menguasai SPSS Untuk Olah \& Interpretasi Data Penelitian,, Yogyakarta, Cahaya Atma.

Yuki, G. A, (2009), Leadership in Organizationals, 4 Ed. Prince Hall, Upper Saddle River, NJ. 